\title{
ENTREVISTA COM LEDA BISOL
}

\section{Como surgiu o seu interesse por Linguística?}

Meu interesse pela área começou no II Instituto Interamericano de Linguística, que se realizou no México, de 27 de novembro de 1967 a 02 de fevereiro de 1968, com minicursos ministrados por professores de diferentes partes do mundo, entre os quais Mattoso Camara Jr. Foi o primeiro curso com o grande mestre. Encantada com a nova perspectiva de estudos da linguagem que se desvendava, pois de minha formação trazia somente conhecimentos de Filologia, tomei, então, todas as providências para realizar o mestrado na área, o que veio a se tornar possível com a Pós-Graduação em Linguística, sob direção de Aryon Dall'Igna Rodrigues e colaboração de Mattoso Camara Jr., que se instituía no Museu Nacional do Rio de Janeiro, onde realizei o mestrado e o doutorado, não subsequentemente.

\section{Conte-nos um pouco sobre sua experiência de Pós-Graduação no exterior.}

Durante o doutorado, estive um ano com bolsa da CAPES na Universidade de Edinburgh, na Escócia, mais especificamente no Laboratório de Fonética, onde realizei todo o trabalho experimental relativo a minha tese, sob a supervisão atenciosa e clarividente de J. A. Kemp. No período, participei de vários cursos, entre os quais os de Abercombrie e Laver, nomes expressivamente presentes na literatura da Fonética. Habituada à leitura em inglês, mas não à fala, o desafio não foi pequeno, mas, em contraparte, os escoceses, que são gentis e amáveis, favoreceram o contato. Dado o imenso frio daquela terra, que ia aos extremos de 10 a 20 graus abaixo de zero, ao chegar ao antigo prédio de Linguística, costumava-se tomar uma "caneca" de chá, na sala aquecida à lareira, onde se deixavam os agasalhos pesados; lá, entre uma breve conversa ou uma escuta descontraída, todos se familiarizavam. E, então, seguia-se para a sala de aula ou de estudos, em geral, coletiva. Compartilhei-a inicialmente com um estudante de finlandês e depois com um islamita que, gentilmente, tentara converter-me ao islamismo. Bons momentos foram vividos não só na universidade, mas também fora dela, deixando da bela cidade de Edinburgh e dos amigos daquela época e daquele lugar uma grata recordação. Com bolsa de PósGraduação do CNPq, estive um ano na Universidade de Stanford, Califórnia, com a felicidade de poder contar com Paul Kiparsky na discussão da pesquisa programada para aquele período: o ditongo no 
português. Em adição, assisti a vários cursos, apresentei o artigo Vowe Harmony in Brazilian Portuguese, no seminário Sociolinguistics Workshop da Universidade de Stanford, que também foi apresentado em New Ways of Analyzing Variation in language (NWAV_XVII), em Montreal, Quebec. Nesse mesmo evento, foi apresentado um segundo artigo em co-autoria com Gregory Guy, Phonological Theory and Variable Data. Ao contrário da experiência escocesa, a norte-americana foi mais solitária, pois a comunicação virtual, via email, que ainda era rara no Brasil, já reinava plenamente, deixando mais tímida a aproximação de um com o outro. Foi uma experiência que tive de aprender. No entanto, esse foi um período muito feliz tanto nos estudos e pesquisas quanto na vida cotidiana.

\section{Como foi a experiência com Mattoso Camara Jr.?}

Fiz todos os cursos de Mattoso Camara no período de mestrado, no Museu Nacional, e, ao voltar ao Rio de Janeiro para o doutorado, ele já não existia. Foi um professor raramente igualável, a Fonologia irradiava dele e contagiava a todos, pois ele concentrava a atenção de seus ouvintes por meio de uma voz que vinha de dentro de sua vivência fonológica, razão de sua vida. Essas aulas ficaram em minha lembrança. Embora tenha feito a minha dissertação de mestrado na área de Sintaxe, "Predicados Complexos", a Fonologia foi minha opção no doutorado: de alguma forma, meu caminho de pesquisa foi marcado pela presença de Mattoso Camara, constante referência em minhas publicações.

\section{Quais são os grandes temas de sua pesquisa?}

Todo assunto que diz respeito à gramática dos sons da linguagem me interessa. Mas meu foco de atenção compreende a fonologia do português brasileiro do norte ao sul do país, a interface entre Fonologia e Morfologia, além da comparação entre o português europeu e o brasileiro. Todavia, alguma investida na gramática histórica também faz parte.

\section{Quais são seus interesses de pesquisa atualmente?}

Estou envolvida em três pesquisas: Variação Linguística no Projeto VARSUL, IV versão, em fase final, realizada com a colaboração dos pesquisadores do sul do país; um estudo sobre a epêntese de consoante, em andamento; e, em fase inicial, uma comparação dos sistemas básicos do português europeu e do brasileiro, com a colaboração de um professor da Universidade do Porto. 


\section{Que contribuições os estudos fonológicos vêm dando à Linguística?}

A partir da ideia de Saussure, início do século XX, segundo a qual há o estudo histórico-comparativo de línguas e o estudo de um estado de língua, a diacronia e a sincronia, colocadas então em lados opostos, são noções que trilham caminhos diferentes. A Fonologia, por sua vez, se consagrou como teoria na linha da sincronia, com os seguidores Trubetzkoy e Jakobson, da Escola de Praga, e Bloomfield e Sapir, da Escola Americana. Houve contribuições de outras vertentes da teoria fonológica que se sucederam para o real conhecimento das gramáticas de sons de línguas faladas no mundo, entre as quais, as minoritárias, como as línguas indígenas do Brasil.

\section{Em sua opinião, quais são os grandes marcos das pesquisas linguísticas contemporâneas?}

Tudo indica que as pesquisas relacionadas ao discurso tomam fôlego, seja com ênfase no sentido, como a Semiótica ou Semiologia, seja com ênfase no uso, como a Pragmática, entre outras. Mas cada área tem a sua faceta privilegiada, como a sintaxe funcional, no âmbito da Sintaxe, e, no âmbito da Fonologia, a teoria da otimidade e a teoria das moras. Isso como uma visão geral, descompromissada, pois outras teorias podem estar pontificando, aqui e acolá, como as demais áreas devem ter os seus domínios privilegiados.

\section{Como você vê o desenvolvimento dos estudos linguísticos no Brasil nos últimos anos?}

O quadro geral do Brasil, resumidamente, é o seguinte: nas universidades em que, ao lado das disciplinas básicas, como Sintaxe, Fonologia e Semântica, cultivam-se teorias relacionadas ao discurso ou texto, o desenvolvimento é o esperado, com resultados significativos e repercussão fora do país. Nas universidades em que, ao contrário, privilegiam-se disciplinas relacionadas ao discurso/texto em detrimento das básicas, o desenvolvimento fica muito a desejar e constitui um dos problemas do Brasil, fato que precisa ser pensado e solucionado.

\section{Em sua opinião, quais seriam as perspectivas para os estudos linguísticos?}

Estudos de interface do tipo Fonologia/Morfologia, Fonologia/Sintaxe, Fonética/Fonologia, linguagem/ensino, ou outras dimensões, como linguagem/Psicologia, lingua(gem)/cérebro etc., abrem inúmeras perspectivas de estudos. Todavia, os velhos temas são sempre novos quando estudados sob 
a perspectiva de uma nova teoria que o desenvolvimento da Linguística oferece, ou quando uma reorganização de dados abre as portas para uma nova visão do fato linguístico. Vale observar que, na área da Sociolinguística, esse dilema, velho e novo, não existe, dada a diversidade de comunidades que falam a mesma língua, sobretudo, em se tratando de um vasto território como o Brasil.

\section{Quais são as maiores dificuldades do pesquisador da área de Letras (Linguística)?}

Uma biblioteca razoável é um requisito, contando-se com a internet para obtenção de artigos que se fizerem necessários com o desenvolvimento da pesquisa. Recomenda-se a participação de bolsistas de iniciação científica que, ao serem treinados, auxiliam o pesquisador em muitas tarefas. Demais dificuldades estão em relação com a infraestrutura da instituição ou com a obtenção de auxílio de entidades de fomento à pesquisa.

\section{Qual é o papel da Linguística na formação de um profissional de Letras?}

A visão da língua como um fato real do conhecimento humano, ou seja, da língua em sua dupla face língua/linguagem, capacidade do ser humano e uso, somente se adquire com a Linguística. Esse saber, ao menos em seus princípios básicos, é indispensável ao profissional de Letras que se dedica ao ensino de língua, por mais habilidades didáticas que possa ter. Embora a gramática normativa venha predominando no ensino fundamental e na graduação com vistas a adquirir a norma culta, um dos objetivos do ensino, o importante é levar o aluno a refletir sobre o que a gramática ensina como normas, respeitando a sua dimensão, mas refletindo sobre elas com fundamentos linguísticos. Assim sendo, a gramática normativa terá os efeitos esperados.

Com você avalia a relação entre as descobertas da Linguística e o ensino de Língua Portuguesa nas escolas, especialmente no que diz respeito à variação e ao preconceito linguístico?

Tanto a norma culta quanto a linguagem da comunidade em que a escola está ou as outras variedades, representadas ou não na fala dos alunos, devem ser foco de atenção do professor que ensina Língua Portuguesa, sobretudo, considerando-se que o português brasileiro caracteriza-se por um grande número de variedades geográficas, em virtude de seu amplo território e formação sociocultural. O ponto de partida pode ser a gramática normativa, 
como uma reflexão sobre a norma estudada que deve incluir a variação decorrente em uso ou vice-versa, a partir desta para aquela, com base na Linguística. Para tanto, é necessário que a Linguística esteja presente na formação do professor, como foi referido na questão anterior.

\section{Como o surgiu o Projeto VARSUL?}

Havendo adquirido certo conhecimento e prática em variação nos cursos de doutorado e no desenvolvimento da minha tese, sob a orientação de Anthony Naro, iniciador e divulgador da análise variacionista no Brasil, ao regressar à UFRGS e dar continuidade a esse tipo de estudo, achei que devia aumentar a amostra que havia coletado, ou seja, organizar nova coleta. Ao falar sobre isso com a coordenadora do Centro de Letras, então, Margot Levi Mattoso, a ideia que nos foi sugerida foi incrementar as três pesquisas da casa: o Atlas Linguístico de Valter Kock, em andamento; o bilinguismo de Margot L. Mattoso, por iniciar; e a variação de Leda Bisol, em proposta de aumento de dados. Assim pensada, a intenção foi levada à diretora de Letras da UFRGS, Nora Thielen, que ofereceu todo o apoio para que de imediato organizássemos uma reunião com vistas a tratativas do projeto, convidando um pesquisador de cada universidade, a federal de Florianópolis e a federal de Curitiba. Assim o fizemos. Para a reunião de variação foram convidados os seguintes professores

que se fizeram presentes: Solange Lira, da Universidade de Santa Catarina e Sergio Faraco, da Universidade do Paraná, um nome assaz conhecido. Assim começou o projeto que levou o nome de VARSUL, Variação Linguística no sul do País.

\section{Qual a importância desse tipo de banco de dados?}

Não só é importante para a descrição do português brasileiro que ainda tem muito por ser estudado, mas também pode ser, por meio de estudos comparativos, uma fonte de evidências para chegar à generalização de certas regras ou argumentos de ideias expostas, contribuindo dessa e de outra forma para o desenvolvimento da teoria fonológica.

\section{O trabalho como professora em sala de aula e como orientadora é ainda estimulante?}

É sempre uma alegria, um desafio, uma realização.

Entrevista realizada em: 24/09/2013. 